\title{
Educação, sustentabilidade e democracia: explicitando a diversidade de projetos político-pedagógicos
}

\section{Education, Sustainability and Democracy: Making the Diversity of Political Pedagogical Projects Explicit}

\author{
Gustavo Ferreira da Costa LIMA*
}

\begin{abstract}
RESUMO
O presente trabalho objetiva discutir a relação entre a educação, a sustentabilidade e a democracia, em diálogo com a proposta de Educação para o Desenvolvimento Sustentável (EDS) protagonizada pela Unesco, por organismos internacionais, sistemas educacionais de países europeus e pela própria produção acadêmica, que lhe dá suporte. Procura avaliar as contradições e implicações dessa proposta no campo que integra a educação e as questões ambientais, bem como explorar as perspectivas abertas à edificação de uma educação complexa e democrática, que incorpore a questão ambiental sob uma perspectiva política e crítica. Trata-se, portanto, de debater e explicitar projetos e intenções socioeducativas e de recuperar a diversidade de visões de mundo, de sociedade e de educação que podemos desejar e construir solidariamente. Para atingir esse objetivo, o artigo dialoga com os referenciais teóricos da Ecologia Política e da Tradição Crítica, e organiza a reflexão em duas instâncias principais: na primeira, formula uma crítica do que considera os aspectos problemáticos da referida proposta; e na segunda, explora as possibilidades de avanço na relação entre a educação e a sustentabilidade, de modo que a democracia participativa, a sociedade civil e suas dimensões ética e política sejam contempladas e fortalecidas.
\end{abstract}

Palavras-chave: educação; sustentabilidade; democracia.

\begin{abstract}
This paper aims to discuss the relationship between education, sustainability and democracy in relation to the Education for Sustainable Development proposal - ESD led by UNESCO, several international organizations, educational systems of European countries, and the scientific production that supports it. It evaluates the contradictions and implications of this proposal on the matters that are related to education and environmental issues, as well as explores the possibilities to build a complex and democratic educational system that assimilates environmental issues under a political and critical perspective. Therefore, it deals with the discussion and explanation of socio-educational projects, and with the intention of redeeming the diversity of world views, society and education that we wish for and can build together. To achieve this task this paper dialogues with theoretical references of Political Ecology and Critical Tradition and organizes the reflection in two moments: in the first one it criticizes the problematic aspects
\end{abstract}

\footnotetext{
* Doutor pelo IFCH-UNICAMP. Professor e pesquisador do Departamento de Ciências Sociais - DCS e do Programa Regional de Pós-Graduação em Meio Ambiente e Desenvolvimento - PRODEMA, da Universidade Federal da Paraíba - UFPB, Sociologia. Email: gust3lima@uol.com.br.
} 
of the proposal mentioned above. In the second it explores the possibilities of building a relation between education and sustainability that integrates and encourages participative democracy, civil society and its ethical and political dimensions.

Key-words: education; sustainability; democracy.

\section{Introdução}

O contexto contemporâneo de crise ambiental, reconhecido globalmente desde fins do século XX, convocou a educação ao desafio de formular caminhos metodológicos e práticas pedagógicas capazes de ampliar a consciência pública sobre os problemas ambientais e promover mudanças de atitude que se refletissem no cotidiano dos indivíduos e no universo macrossocial dos governos, das empresas e das organizações não governamentais. Para atender a essa convocação, a educação ambiental (EA) se constituiu globalmente, nas últimas quatro décadas, como um campo de conhecimento, de atividades e políticas públicas de grande diversidade, permeado por muita polêmica, mas que gradualmente amadurece suas propostas, explicita seus pontos de debate, define e constrói teorias e metodologias para educar o público discente, formar docentes, implementar e avaliar suas práticas.

A partir de década de 1990, à medida que o discurso do desenvolvimento sustentável se consolidava como expressão hegemônica nos debates envolvendo desenvolvimento e meio ambiente, a categoria do desenvolvimento sustentável inseriu-se numa multiplicidade de campos sociais, entre os quais o campo educacional, fazendo emergir a proposta de Educação para o Desenvolvimento Sustentável (EDS) ou de Educação para a Sustentabilidade. Tal proposta, protagonizada pelas Nações Unidas, pela Unesco, pelas políticas educacionais de diversos países europeus e pela produção acadêmica internacional que lhe dá sustentação, acabou se institucionalizando como uma renovação discursiva, a ponto de ter sido abordada pela Unesco como tema da Década da Educação para o Desenvolvimento Sustentável no período 2005-2014 (STERLING, 2001; TILBURY, 1996; SAUVÉ, 1997).

Com base no exposto, o presente trabalho pretende discutir a relação entre a educação, a sustentabilidade e a democracia, considerando as implicações e contradições da proposta oficial de Educação para o Desenvolvimento Sustentável e as possibilidades abertas à construção de uma educação democrática e complexa, que incorpore a questão ambiental de maneira transversal, estimulando a participação social e uma perspectiva crítica de compreender e interagir com a relação entre sociedade e ambiente. Dito dessa maneira, pode parecer que o que ora se apresenta é uma discussão meramente semântica. Ao contrário, trata-se de debater e explicitar projetos e intenções políticas e socioeducativas e de recuperar a diversidade de mundos e de relações sociais que podemos desejar e construir solidariamente. Tentar compreender quais são os objetivos dessa renovação discursiva. Educar para sustentar o quê, por que e para quem? Qual a diversidade de leituras sobre esse debate e quais os argumentos favoráveis e contrários a ele? Que fundamentos, valores e interesses estão envolvidos nesse processo?

Para atingir esse objetivo, propõe-se uma reflexão em duas instâncias principais: na primeira, faz-se uma crítica do que se consideram os pontos problemáticos da referida proposta; e na segunda, discutem-se as possibilidades de construir a relação entre a educação e a sustentabilidade de modo que a democracia participativa, a sociedade civil e as dimensões éticas e políticas dessa relação sejam reafirmadas e fortalecidas.

Essa reflexão se apoia nos e dialoga com os pressupostos teóricos da Ecologia Política e da Tradição Crítica que compreende um campo amplo de pensamento à esquerda, que congrega autores marxistas, neomarxistas e frankfurtianos preocupados com a interrelação que se estabelece entre as questões ambientais, a cultura e as estruturas sociais e políticas.

A Ecologia Política emergiu como um campo de saber nas décadas finais do século XX, a partir da crítica e da politização dos problemas ambientais, de sua gênese, suas consequências, contradições e possíveis alternativas. Nesse sentido, trouxe a contribuição crítica das ciências humanas e sociais para a reflexão e o debate ecológico, até então pautado por leituras biologicistas e despolitizadas dos problemas ambientais. Procura, justamente, incorporar ao debate aqueles elementos que as visões disciplinares deixavam fora da análise, como os modelos de desenvolvimento econômico-social, os interesses e conflitos de 
classe, os padrões culturais e ideológicos e as injunções políticas dominantes. E embora essa abordagem política das questões ambientais tenha se notabilizado pelas contribuições de Andre Gorz, Jean Pierre Dupuy, Cornelius Castoriadis, Murray Bookchin, Marcuse, Moscovici e Edgar Morin, entre outros, estendeu-se pelas gerações seguintes, inspirando diversos autores contemporâneos nacionais e internacionais (ALPHANDÈRY et al., 1992; LIPIETZ, 2000; LOUREIRO, 2003).

A tradição crítica, em sentido convergente, enfatiza a motivação política e a abordagem relacional da pesquisa, associando o problema investigado ao contexto histórico de sua emergência, partindo de uma posição de não neutralidade ideológica e de compromisso com os problemas concretos da sociedade (ALVES-MAZZOTTI, 1996).

\section{Crítica à proposta de educação para o desenvolvimento sustentável}

Ressalta, em primeiro lugar, o caráter instrumental da proposta no sentido de que se está propondo educar pessoas para um objetivo específico, em que a educação serve como meio para alcançar outra coisa, e portanto não tem um fim em si mesma Esse pressuposto contraria o espírito da educação enquanto prática de liberdade que pressupõe autonomia e pensamento crítico. Nesse exercício de liberdade, o aluno é estimulado a pensar, relacionar-se, fazer escolhas e agir por si próprio e não orientado por uma finalidade predeterminada. Para Jickling (1992), uma educação orientada para uma finalidade determinada sugere mais um adestramento para a aquisição de certas habilidades do que um aprendizado envolvido com a compreensão. No caso da EDS ele argumenta:

É importante notar que essa posição se apóia em algumas suposições. Primeiro, supõe que o desenvolvimento sustentável é um conceito incontestável e, segundo que a educação é uma ferramenta para ser usada para seu avanço. O primeiro ponto é claramente falso e deve ser rejeitado; existe considerável ceticismo sobre a coerência e eficácia do termo. A segunda suposição também pode ser rejeitada. A prescrição de uma perspectiva particular é incongruente com o desenvolvimento do pensamento autônomo. (JICKLING, 1992, p. 8).

Em segundo lugar, a instrumentalidade acima mencionada torna-se ainda mais problemática quando se constata que o desenvolvimento sustentável, enquanto objetivo proposto para a educação, revela ampla polissemia e múltiplas ambiguidades. Vejamos algumas das principais.

Em sua versão oficial, divulgada pelo Relatório Brundtland, em 1987, e consagrada a partir da Conferência do Rio, em 1992, o desenvolvimento sustentável se define como "aquele que responde às necessidades das gerações presentes sem comprometer a capacidade das gerações futuras atenderem suas próprias necessidades" (BRUNDTLAND, 1991). Embora reconheçamos alguns aspectos inovadores de sua formulação - que, infelizmente, não poderemos discutir aqui ${ }^{1}$-, é necessário constatar o tom impreciso e vago da definição que, por isso mesmo, acaba permitindo múltiplas leituras a partir dos interesses e valores dos indivíduos ou grupos sociais que dele se utilizam. Exemplo disso se observa na revisão da literatura sobre o tema, que permite contabilizar dezenas de definições diferentes sobre o que vem a ser o Desenvolvimento Sustentável e sobre os caminhos mais adequados para atingi-lo. São definições não apenas diferentes, mas muitas delas com significados antagônicos entre si (REDCLIFT, 2006). Esse fato sugere a existência de um campo social, no sentido empregado por Pierre Bourdieu (2001, 2004), e que uma multiplicidade de discursos - e de grupos sociais - disputam a legitimidade e a hegemonia sobre ele, assim como o poder de orientá-lo segundo seus interesses e concepções.

Sabe-se que o desenvolvimento sustentável tem se caracterizado, tanto retoricamente quanto, sobretudo, na prática, por uma ênfase - ou reducionismo - econômica que transparece na prioridade das políticas de crescimento frente a objetivos concorrentes, na argumentação sobre as necessidades do crescimento para superar a pobreza, na distribuição dos investimentos e da poupança social contra outras finalidades, e nas decisões políticas a favor de metas econômicas em todos os conflitos que oponham a economia, a sociedade e o meio ambiente (VEIGA, 2005; GUIMARÃES, 1995; DUPAS, 2008). Assim, embora tenha uma retórica multidimensional que promete compatibili-

${ }^{1}$ Para maiores detalhes sobre o assunto ver: LIMA, 2003. 
zar viabilidade econômica, justiça social e preservação ambiental, a ênfase é sabidamente de defesa assimétrica do crescimento econômico. Nesse caso, ao incorrer em reducionismo econômico, essa orientação hegemônica da sustentabilidade não só contradiz a retórica como sacrifica a multidimensionalidade e a interdisciplinaridade, categorias centrais da sustentabilidade.

Nesse caso, é preciso voltar à questão: sustentar o quê? E para quem? A preservação ambiental, o bem-estar social ou a reprodução da acumulação capitalista? E, ainda, a sustentabilidade é para todos ou para alguns privilegiados?

O otimismo tecnológico é outro elemento central, tanto na teoria quanto na prática, do desenvolvimento sustentável e define-se pela crença de que o avanço científico-tecnológico não só é capaz de produzir tecnologias limpas, de baixo impacto, como também representa uma fonte inesgotável de soluções para os problemas vivenciados. E é um argumento central justamente porque autoriza a manutenção do status quo como a caixa mágica de ferramentas que permite e promete reformas dentro da mesma ordem e dos mesmos modelos de produção e consumo dominantes. Essa crença, no entanto, não se sustenta quando constata-se que o próprio desenvolvimento tecnológico é responsável por uma grande proporção dos problemas ambientais contemporâneos, alguns destes de caráter irreversível, como é o caso do desaparecimento de espécies animais e vegetais, da perda de solo fértil, da transformação de florestas em zona urbana e de fenômenos como a mudança climática (SACHS, 2002; GIDDENS, 1997, 1999; BECK, 1992). Essa crítica, contudo, não quer dizer que a tecnologia não tenha uma contribuição importante hoje e que possamos dispensá-la. Ao contrário, a tecnologia é simultaneamente parte do problema e da solução, mesmo porque ela é decisiva para diagnosticar e tratar inúmeros impactos ambientais. Apenas propõe-se que a tecnologia seja encarada como um instrumento subordinado à decisões políticas, éticas e sociais que a definem e não na ordem inversa que lhe atribui vida própria e onipotência.

A questão política que define o papel da cidadania, da participação social e do modelo de democracia é outra questão central na relação entre educação e sustentabilidade, que parece fragilizada tanto no discurso do desenvolvimento sustentável quanto no da EDS. E por quê? Porque são, por princípio, propostas impositivas, definidas de cima para baixo, que não envolvem consulta e participação pública na discussão dos fins a serem perseguidos, na formulação e decisão das políticas a serem implementadas. Em geral, o público é convocado a participar e colaborar da execução de planos e projetos predefinidos pelas elites econômicas e políticas, ou seja, participam para executar e legitimar decisões e prioridades eleitas sem seu consentimento. A cidadania e a participação social são bastante invocadas no debate sobre a educação ambiental, em geral desrelacionadas de uma crítica sobre a dubiedade implícita no conceito liberal de cidadania. Refiro-me ao fato dessas noções serem, no contexto do capitalismo, frequentemente usadas como meios de ocultar as desigualdades sociais e de legitimar sua manutenção. Cabe, portanto, lembrar que a outorga de uma igualdade jurídica formal, desacompanhada de outras conquistas econômicas, sociais e políticas, converte a cidadania num mero artifício para camuflar e perpetuar a exploração capitalista sobre a sociedade e a natureza (ALVES, 2000).

Em trabalho anterior, discuti a ambiguidade e a banalização do uso das noções de cidadania e participação social nos discursos oficiais de educação ambiental - incluído o caso brasileiro -, como de resto nos discursos liberais, e a necessidade de diferenciar um modelo de participação e cidadania passiva, conservadora e tutelada de um outro modelo ativo, transformador e autônomo (LIMA, 2003; CARVALHO, 1991; VIEIRA, 1998; DEMO, 1995).

Até o momento, algumas evidências demonstram que o discurso oficial do desenvolvimento sustentável que detém a hegemonia do campo é o discurso proveniente dos organismos internacionais - Unesco, ONU, BID e Banco Mundial - e dos chamados países desenvolvidos, delimitado nos marcos da economia capitalista e da regulação do mercado sobre as esferas do Estado e da sociedade civil. Tal discurso se apoia em uma estratégia conciliatória e reformista, que propõe mudanças superficiais de ordem tecnológica, demográfica e econômica, em detrimento de outras mudanças políticas, éticas e sociais. Nesse sentido, alguns autores tendem a definir a estratégia do Desenvolvimento Sustentável como um tipo de "modernização conservadora" que simula e ensaia mudanças apenas para garantir que tudo permaneça como está (GUIMARÃES, 1995; LEFF, 2001; PORTO-GONÇALVES, 2004; DIEGUES, 1992). Olhando por essa perspectiva, o que pensar sobre uma educação dirigida para o Desenvolvimento Sustentável? 


\section{Possibilidades de construção de uma educação sustentável e democrática}

Tendo visto os limites e contradições da proposta de EDS, cabe perguntar o que é possível fazer, em que direções podemos avançar? Como relacionar a educação, a sustentabilidade e a democracia de uma maneira construtiva, crítica e transformadora?

Creio que uma primeira contribuição seria a de formar cidadãos críticos, capazes de: pensar, fazer escolhas e agir com autonomia; compreender a dinâmica e as implicações da relação entre a sociedade e o meio ambiente em suas múltiplas dimensões e de diferenciar os significados dos vários discursos e práticas socioambientais quanto às suas concepções político-ideológicas, seus objetivos, interesses e valores. Esse objetivo tende a promover o educando enquanto sujeito social e a imunizá-lo das propostas adestradoras e reducionistas (TOURAINE, 1994).

Também é possível, em sentido convergente, politizar a compreensão da crise ambiental, problematizando temas e conceitos como os de democracia, esfera pública, cidadania ambiental, participação e justiça socioambiental, riscos tecnológicos, cidadania científica, conflitos e responsabilidade socioambientais. Em tal exercício, importa discutir os limites do conceito liberal de cidadania, as diferenças entre cidadania ativa e passiva, entre uma participação tutelada e outra conquistada, entre democracia representativa e participativa; o direito universal ao acesso e usufruto dos bens naturais e a um ambiente saudável; a disputa pelo acesso e uso dos bens naturais entre interesses públicos e privados; a responsabilização dos agentes da degradação, considerando o princípio de que as responsabilidades são comuns, mas diferenciadas segundo a proporção do impacto causado pelos diversos agentes, os direitos a participar na definição dos limites danosos da pesquisa científica e aplicação tecnológica, a responsabilidade com as gerações futuras e com as demais espécies que dividem e mantêm a comunidade da vida conosco (DEMO, 1995, 1999; SERRES, 1991; BECK, 1992; GIDDENS, 1999; ACSELRAD, 1992; ESTY; IVANOVA, 2005). Essa politização e democratização da educação e da sustentabilidade, no sentido sugerido, questiona o projeto hegemônico de um desenvolvimento orientado pelo mercado que converte a natureza em recursos para a reprodução do capital, o ser humano e suas relações em capital social e a educação em mero ins- trumento de formação para o mercado de trabalho. Afirma, contrariamente, a primazia da sociedade civil articulada a um estado forte, democrático e participativo como únicos caminhos para conter os excessos do mercado (SACHS, 1994; GUIMARÃES, 1995; LIMA, 2003).

Essa politização da questão ambiental também pode ser estendida ao universo escolar, com o intuito de democratizar e ambientalizar tanto o espaço físico escolar quanto as relações entre professores, alunos, diretores e funcionários. Essa extensão de uma ecopolítica escolar tem muito a ganhar ao incluir e fortalecer as relações com a comunidade de seu entorno. No caso, isso pode ser entendido como um incentivo às práticas participativas, cooperativas e dialógicas de inclusão dos diversos atores sociais, de aprendizagem compartilhada e de ação conjunta em parcerias e projetos de interesse mútuo.

Democratizar e ambientalizar a educação também significa desenvolver teorias e metodologias coerentes com o processo de mudança socioambiental desejado. Por um lado, significa explicitar os conceitos e teorias utilizadas e os contextos históricos e político-epistemológicos de onde provêm; por outro lado, faz-se necessário construir metodologias e didáticas capazes de traduzir as teorias referenciadas ao cotidiano escolar. Essas duas lacunas, teórica e metodológica, articulam-se perversamente, ora produzindo práticas educativas reprodutoras e reducionistas e, portanto, contrárias à teoria que a inspirou, ora resultando em um vazio prático que acaba sendo preenchido com práticas igualmente reducionistas, porque a teoria não encontrou uma metodologia e uma didática capazes de traduzi-la com coerência à linguagem dos educandos receptores. (SILVA, 2009). E, naturalmente, essa questão não só envolve as dificuldades inerentes aos processos de mudança paradigmática e de produção de conhecimento em um campo de conhecimento recente, como também a carência histórica de formação e capacitação dos professores partícipes neste processo de ensino e aprendizagem.

Por último, julgo necessário constatar que a crise ambiental dos séculos XX e XXI apresenta para a sociedade e, especialmente, para a educação desafios de ordem cultural e ética de grandes proporções, que anseiam por mudanças valorativas, de visões e estilos de vida. Nesse contexto, a ideia de aprendizado social adquire importância central no debate da sustentabilidade e da mudança paradigmática. O tipo de vida, de sociedade e educação que teremos no futuro vai depender da qualidade, do significado e da ex- 
tensão dos processos de aprendizado que formos capazes de construir e exercitar individual e socialmente. A educação e os educadores, em especial, que concentram as tarefas de conceber e implementar os modelos de ensino e aprendizagem sociais têm uma responsabilidade singular nesse processo. Refletindo sobre a contribuição da educação nos processos de crise social como as que vivenciamos Sterling lembra Einstein quando pondera: Nenhum problema pode ser resolvido a partir da mesma consciência que o criou. Precisamos aprender a ver o mundo renovado (EINSTEIN apud STERLING, 2001). Para Sterling, precisamos ver de forma distinta, deslocar e renovar nossos pontos de vista para agir diferentemente. Aprendizado e mudança são inseparáveis, pois não é possível mudar sem aprender (ver o novo), ou aprender algo novo sem mudar de perspectiva (STERLING, 2001).

Clark (1989) discute a ideia de sociedade aprendiz e define-a como aquela capaz de se autocriticar, autocompreender e criar novas visões de mundo e cursos de ação, de acordo com a necessidade histórica. Essa concepção de sociedade aprendiz transcende os limites de uma sociedade que se reduz aos objetivos de produzir e reproduzir-se. Supõe outras capacidades como: autoconhecer-se e conhecer seu ambiente numa perspectiva dinâmica; refletir e tirar conclusões do resultado de suas ações, inclusive as não exitosas; discernir os momentos em que mudanças se impõem, ter a flexibilidade de implementar as mudanças julgadas necessárias, fazer escolhas inteligentes e priorizar iniciativas cooperativas, entre outras qualidades. Está claro que a vida exige ambas as situações: repetição e criação, estabilidade e mudança, ordem e liberdade são faces inseparáveis e complementares da realidade, que assumem a condição de prioridade relativa em cada conjuntura histórica. As características dos atuais modelos de sociedade e de educação demonstram que eles têm sido desproporcionalmente governados por princípios instrumentais, mecânicos e competitivos. Esse ambiente conjuntural tanto reduz as possibilidades da reflexividade e da criatividade prosperarem no meio social, quanto dão sinais de que estamos no pico de uma onda de mutação, que pode ser bem ou mal aproveitada (CLARK, 1989).

Construir, portanto, uma educação ambiental complexa, capaz de responder a problemas igualmente complexos, implica ir além de uma sustentabilidade de mercado reducionista, conservadora e antidemocrática. Pressupõe a capacidade de aprender, criar e exercitar novas concepções e práticas de vida, de educação e de convivência - individual $^{2}$, social e ambiental - capazes de substituir os velhos modelos em esgotamento.

BECK, U. Risk Society. Beverly Hills: Sage, 1992.

BOURDIEU, P. Lições da aula. São Paulo: Editora Ática, 2001. Os usos sociais da ciência: por uma sociologia clínica do campo científico. São Paulo: Editora UNESP, 2004.

BRUNDTLAND, G. H. Nosso futuro comum. Rio de Janeiro: FGV, 1991.

CARVALHO, I. C. M. Territorialidades em luta: uma análise dos discursos ecológicos. São Paulo: Instituto Florestal; Secretaria do Meio Ambiente, 1991. Série Registros. n. 9. p. 1-56.

CLARK, M. Ariadne's thread: the search for new ways of thinking. [s.L.]: Macmillian, Basingstoke, 1989.

ALVES-MAZZOTTI, A. J.; GEWANDSZNAJDER, F. $O$ método nas ciências naturais e sociais: pesquisa quantitativa e qualitativa. São Paulo: Pioneira Thomson Learning, 2002.

\footnotetext{
${ }^{2}$ Refiro-me aos processos de autoconhecimento, na linha de uma ecosofia da subjetividade humana sugerida por Guattari (1990), que está intimamente associada à forma como nos relacionamos com a sociedade e o ambiente.
} 
DEL CASTILLO, L. L. As metodologias para implantação da agenda 21 na escola com ênfase no papel das prefeituras: Estudo de casos no Nordeste brasileiro e em Catalunha (Espanha). João Pessoa, Dissertação (Mestrado em Desenvolvimento e Meio Ambiente) - PRODEMA/UFPB, 2009.

DEMO, P. Cidadania tutelada e cidadania assistida. Campinas: Autores Associados, 1995.

Participação é conquista: noções de política social participativa. São Paulo: Cortez, 1999.

DIEGUES, A. C. Desenvolvimento sustentável ou sociedades sustentáveis: da crítica dos modelos aos novos paradigmas. São Paulo em Perspectiva, v. 6, n. 1-2, p. 22-29, 1992.

DUPAS, G. Meio ambiente e crescimento econômico: tensões estruturais. São Paulo: Ed UNESP, 2008.

ESTY, D. C.; IVANOVA, M. H.(Orgs.) Governança ambiental global: opções e oportunidades. São Paulo: Ed. SENAC, 2005.

GIDDENS, A. A vida em uma sociedade pós-tradicional. In: GIDDENS, A.; BECK, U.; LASH, S. Modernização reflexiva: política, tradição e estética na ordem social moderna. São Paulo: Ed. UNESP, 1997.

. A terceira via: reflexões sobre o impasse político atual e o futuro da social-democracia. Rio de Janeiro: Record, 1999.

GUATTARI, F. As três ecologias. Campinas: Papirus, 1990.

GUIMARÃES, R. P. O desafio político do desenvolvimento sustentado. Lua Nova, n. 35, p. 113-136, 1995.

JICKLING, Bob. Why I don't want my children to be educated for sustainable development. Journal of Environmental Education, v. 23, n. 4, p. 5-8, 1992.

LEFF, E. Saber ambiental: sustentabilidade, racionalidade, complexidade, poder. Petrópolis: Vozes, 2001.

LIMA, G. F. da C. O discurso da sustentabilidade e suas implicações para a educação. Ambiente \& Sociedade, v. 6, n. 2, p. 99-119, 2003.
LIPIETZ, A. A ecologia política: solução para a crise da instância política? In: ALIMONDA, H. (ed.). Ecologia política. Buenos Aires: CLACSO, 2002.

LOUREIRO, C. F. O movimento ambientalista e o pensamento crítico. Rio de Janeiro: Quartet, 2003.

PORTO-GONÇALVES, C. W. O desafio ambiental. Rio de Janeiro: Record, 2004.

REDCLIFT, M. R. Sustainable development (1987-2005) - an oxymoron comes of age. Horizonte Antropológico, v.12, n. 25, p. 65-84, 2006.

SACHS, I. Estratégia de transição para o século XXI. Cadernos de Desenvolvimento e Meio Ambiente, n. 1, p. 47-62, 1994.

Caminhos para o desenvolvimento sustentável. Rio de Janeiro: Garamond, 2002.

SAUVÉ, L. Educação ambiental e desenvolvimento sustentável: uma análise complexa. Revista de Educação Pública, v. 6, n. 10, p. 72-103, 1997.

SERRES, M. O contrato natural. Rio de Janeiro: Nova Fronteira, 1991.

SILVA, L. F. Educação ambiental crítica: entre ecoar e recriar. São Paulo, Tese (Doutorado em Educação) - USP, 2009.

STERLING, S. Sustainable education: re-visioning learning and change. Bristol: Green Books, 2001.

TILBURY, D. Environmental education for sustainability in Europe: philosophy into practice. Environmental Education and Information, v. 16, n. 2, p. 123-140, 1996.

TOURAINE, Alain. Qu'est-ce que la démocratie? Paris, 1994.

VEIGA, J. E. Desenvolvimento Sustentável: o desafio do século XXI. Rio de Janeiro: Garamond, 2005.

VIEIRA, L. Cidadania e globalização. Rio de Janeiro: Record, 1998. 